\section{Desencuentros en las izquierdas y reacciones contrarias a la Asamblea del Pueblo en Concepción (Chile, 1972)*}

Disagreements inside the left-wings and conflicting reactions towards the People's Assembly in Concepción (Chile, 1972)

José DíAz Nieva*

Mario Valdés URrutia ${ }^{* * *}$

\section{Resumen}

En esta investigación examinamos el papel político jugado por la Asamblea del Pueblo formada en Concepción (1972) y las reacciones

\footnotetext{
* Este trabajo se enmarca dentro del proyecto de investigación "La experiencia de la Unidad Popular en Concepción", (código O18767), financiado por la Universidad Santo Tomás (Chile); y la colaboración académica de la Universidad de Concepción.

** Dr. en Derecho Universidad Santo Tomás (Santiago) jdniev@gmail.com Universidad Santo Tomás, Sede Santiago. Ejército Libertador № 146 Santiago (Chile)

*** Dr. en Historia Universidad de Concepción mvaldes@udec.cl Casilla 160 - C Concepción (Chile)
}

contrarias que generó tanto al interior de la Unidad Popular como desde la oposición política en la capital penquista.

Formada la Asamblea del Pueblo por iniciativa de una parte de la Unidad Popular, el Movimiento de Izquierda Revolucionaria (MIR) y bases de izquierdas en la ciudad de Concepción, sus propuestas apuntaban a realizar la revolución desde la población popular, apartándose de la institucionalidad vigente. Este planteamiento provocó el rechazo de Allende y del Partido Comunista a la Asamblea del Pueblo, generando una discusión en la cual el gobierno impuso su visión del camino revolucionario a transitar. Por otra parte, hubo también un esperable y fuerte rechazo a la Asamblea del Pueblo desde el Partido Demócrata Cristiano y desde el derechista Partido Nacional.

Palabras clave: Unidad Popular, Concepción, Asamblea del Pueblo, Poder Popular, 1972.

\begin{abstract}
In this research we examine the political role played by the People's Assembly formed in Concepción (1972) and the opposite reactions that it caused both within the Popular Unity and from the political opposition in the same city.
\end{abstract}

The People's Assembly was founded at the initiative of a part of the Popular Unity, the Revolutionary Left Movement (RLM) and leftist bases in the city of Concepción. Its proposals aimed at carrying out the revolution from the poorest strata of society, leaving aside the prevailing institutions. This approach provoked the rejection of Allende and the Communist Party, 
generating a discussion in which the government imposed its vision of the revolutionary path to follow. On the other hand, there was also an expected and strong rejection of the People's Assembly from the Christian Democratic Party and the right-wing National Party.

Key words: Popular Unity, Concepción, Popular Assembly, Popular Power, 1972.

\section{Introducción}

La Guerra Fría estuvo presente con distinta intensidad en el hemisferio americano. La Revolución Cubana de 1959 y su posterior giro hacia el marxismo estimuló la lucha política de algunos grupos de izquierda que apostaron por la vía insurreccional (Agüero 2016). Expresión de lo anterior fue la formación en Cuba de la Organización Latinoamericana de Solidaridad, en 1967, entidad que intentó coordinar la acción revolucionaria de algunas de esas agrupaciones (Whelan 1993). El ejemplo del Che Guevara en Bolivia, pese a su cruento asesinato, o precisamente por ello, se convirtió además en el ejemplo a seguir (Correa et al. 2001). No cabe duda que la década de 1960 conoció una radicalización política de la que Chile no estuvo ausente: en 1965 surgió el Movimiento de Izquierda Revolucionaria (MIR), formación que apostaba por la "liquidación del aparato represivo burguésy su reemplazo por la democracia directa proletaria y las milicias armadas de obreros y campesinos", único camino para terminar con el atraso y la dependencia (Programa MIR, 15.08.1965; Goicovic, 2016: 99 - 100). Por su parte, el Partido Socialista en su congreso de Chillán (en 1967) declaraba que "como organización marxista-leninista plantea la toma del poder como objetivo estratégico a cumplir por esta generación, para instaurar un estado revolucionario", no descartando la "violencia revolucionaria", la cual consideró "inevitable y legítima", dado que "las formas pacíficas o legales de lucha no conducen por sí mismas al poder". EI PS consideraba como limitados los usos y procedimientos de la democracia formal, no descartando, en última instancia, el empleo de esa "lucha armada" como último e irremediable paso (Jobet 1987:313). El enfoque del PS difirió del planteamiento de los comunistas chilenos, para quienes había que privilegiar las alianzas con otros sectores políticos y la vía electoral para alcanzar el poder público, y desde allí desplegar las transformaciones estructurales que llevarían a la construcción del socialismo. No obstante, y tal como lo interpretó un destacado dirigente socialista de esos años, Carlos Altamirano, y en lo que se refiere a esa radicalización del socialismo, podría afirmarse que enunciados como el expresado se enmarcaban más bien en un discurso retórico de la época que en un firme convencimiento de "la creación de grupos armados" (Salazar 2011: 144-151; 174).

De otra parte, en 1957 surgió el Partido Demócrata Cristiano, entidad que recibió el apoyo de un sector de la Iglesia Católica y que terminó llevándose buena parte de las bases del derechista Partido Conservador. El PDC pronto logró levantar un proyecto propio de transformación de la sociedad chilena, presentándose como una fuerza política popular y partidaria de reforzar el protagonismo de los cuerpos intermedios de la sociedad. EI PDC se presentaba como una fuerza equidistante de la derecha y de la izquierda, una especie de tercera posición que apostaba por cambios tendientes a redistribuir el ingreso y hacer realidad la participación democrática de la ciudadanía. Con la consigna Revolución en Libertad lograba 
llevar a Eduardo Frei a la presidencia en 1964; aunque en 1970 con el Triunfo Popular -slogan enarbolado por Tomic- sufría un duro revés.

Los años sesenta conocieron también casi la total expulsión de la derecha del Parlamento ((L et al. 2006). Los partidos Conservador y Liberal sufrieron un fuerte detrimento de sus apoyos electorales; en gran medida por verse forzados a apoyar lo que consideraban el mal menor -Frei- en las elecciones presidenciales de 1964; era eso o enfrentar la posibilidad de la llegada de un socialista marxista a la presidencia. Tras la mayor derrota electoral de su historia en las elecciones parlamentarias de 1965 , en las cuales perdió todos sus senadores (excepto aquellos que no renovaban su cargo), y en las que apenas logró elegir 9 diputados, conservadores y liberales suscribieron la iniciativa de una pequeña agrupación nacionalista -Acción Nacional- para formar un nuevo referente derechista: el Partido Nacional. (Díaz y Valdés 2015a). Esta nueva derecha se opuso al gobierno de Frei -y al de Allende-, realizando continuos llamados a la participación de las Fuerzas Armadas para garantizar una institucionalidad que estimaba amenazada por el marxismo (EDI 17.03.1966; PN, 1967).

Antes y después de 1970 hubo diversas posturas en las izquierdas frente a la cuestión de cómo llevar a cabo una transformación del Estado burgués al socialismo. Esta polémica recrudeció a propósito de la iniciativa en la Unidad Popular de Concepción por impulsar una asamblea popular, de cara a la formación de un poder alternativo al oficial, lo cual concitó la oposición del Partido Comunista y del presidente Allende, quienes, junto con rechazar la aceleración del proceso revolucionario con el protagonismo popular planteado por la Asamblea del Pueblo, insistían en la tesis del avance revolucionario por la vía institucional. Hubo aquí una colisión entre los revolucionarios de abajo y los políticos de arriba, por utilizar la expresión de Peter Winn (2004). Asimismo, la asamblea penquista no fue bien vista en la oposición derechista, interpretándola como un eslabón más de la cadena que llevaba irremediablemente al país a la dictadura del proletariado.

En el presente trabajo se examina la propuesta de convocar la Asamblea del Pueblo, su realización y las repercusiones que concitó. El énfasis está colocado en la reacción del gobierno y en el esclarecimiento de la postura proveniente desde la oposición frente a las iniciativas políticas procedentes de la referida asamblea; es decir, frente a la propuesta de Poder Popular y organización alternativa al gobierno oficial. Para ello se ha consultado la prensa y las revistas de la época (principalmente Santiago y Concepción), los debates parlamentarios, los discursos y declaraciones de diversos personeros políticos y gremiales y las memorias de los protagonistas.

La Asamblea del Pueblo en Concepción significó un problema para el gobierno de Allende y para la mayoría de los partidos que componían la coalición que lo respaldaba. A la resistencia que produjo la iniciativa de Poder Popular en el gobierno y, especialmente, en el Partido Comunista, hubo de sumarse el rechazo de la oposición de derecha, la cual utilizó las propuestas de dicha Asamblea como un argumento más para descalificar y deslegitimar el gobierno, acusándole de llevar a cabo una gestión ilegal y profundamente antidemocrática. De manera tal que se observa en la derecha un incremento de sus actividades políticas -ahora de "Resistencia Civil"- frente al gobierno 
popular en el segundo semestre de 1972, previo a la realización de las elecciones parlamentarias de marzo de 1973 (Valdivia 2008: 304-305).

Nunca hubo unanimidad en las izquierdas para resolver la mejor vía de realizar la revolución. Pero Allende lideró la tesis que prevaleció, no obstante, el surgimiento en Concepción de una alternativa revolucionaria que surgió desde el MIR y de amplios sectores del PS, el Movimiento de Acción Popular Unitario (MAPU) y la Izquierda Cristiana (IC). De ahí que pretendemos responder preguntas relacionadas con el porqué del rechazo a la alternativa concebida por esta especial reunión política penquista.

La Asamblea del Pueblo en Concepción no ha concitado mayor interés historiográfico, de no mediar el trabajo de Danny Monsálvez Araneda ("La Asamblea del Pueblo en Concepción. La expresión del Poder Popular" 2006) y la segunda parte del libro de Franck Gaudichaud, (Chile 1970-1973. Mil días que estremecieron al mundo Poder Popular, cordones industriales y socialismo durante el gobierno de Salvador Allende, $1^{\text {a }}$ edición castellana, 2016); aunque hay que indicar que el hecho histórico que nos interesa también ha sido aludido en los trabajos sobre la izquierda durante la UP de Luis Corvalán (1997), Igor Goicovic (2012) y Julio Pinto (2005). Por todo lo anterior se considera que resulta pertinente la revisión de este particular proceso.

\section{La senda hacia la Asamblea del Pueblo}

El programa de gobierno de Salvador Allende indicaba que se colocarían las bases para transitar hacia una sociedad socialista en democracia y libertad, respetando la Constitución y las leyes. Pero antes había que ganar la elección presidencial, tarea para la cual se organizaron los Comités de Unidad Popular, "articulados en cada fábrica, fundo, población, oficina o escuela por los militantes de los movimientos y de los partidos de izquierda e integrados por esa multitud de chilenos que se [definían] por cambios fundamentales". Estos comités fueron definidos también como "expresiones germinales de Poder Popular", porque precisamente los trabajadores se prepararían "para ejercer" dicho poder en ese "nuevo Estado" que se articularía (Programa Gobierno UP, 1969: 11; 13; 47). Por otra parte, dentro de las iniciativas contenidas en el mismo programa, con respecto a una nueva organización estatal se mencionaba la propuesta de instalar una cámara única dentro de un nuevo orden institucional:

\footnotetext{
"Una nueva Constitución Política institucionalizará la incorporación masiva del pueblo al poder estatal. Se creará una organización única del Estado estructurada a nivel nacional, regional y local que tendrá a la Asamblea del Pueblo como órgano superior de poder. La Asamblea del Pueblo será la Cámara Única que expresará nacionalmente la soberanía popular. En ella confluirán y se manifestarán las diversas corrientes de opinión" (Ibid.).
}

Para Rodrigo Ambrosio, dirigente del MAPU, "el pueblo" llegaba al gobierno el 4 de noviembre de 1970 con Allende, "pero no será poder"; aunque lucharía por él "desde esa posición". Frente a las preguntas de un periodista de cómo plantearía el nuevo gobierno la reorganización de la institucionalidad estatal, respondió que éstas se deberían subordinar

\footnotetext{
"a un organismo superior de poder, la Asamblea del Pueblo, elegida y revocable democráticamente en la que estarán proporcionalmente representadas todas las tendencias. En esa Asamblea se manifestará de manera directa la voluntad popular, porque las demás instituciones del Estado no constituirán poderes paralelos y en mutuo equilibrio, sino poderes subordinados, esa
} 
voluntad podrá traducirse en actos de manera coherente y eficaz... El Estado chileno de hoy es un Estado concebido para compartimentar la voluntad popular, alejarla de las masas y hacerla inocua en los mil laberintos burocráticos. Incluso las fracciones avanzadas de la burguesía se han visto obstaculizadas en sus intentos reformistas por esa organización esencialmente conservadora del Estado" ( $C$, 12.11.1970: 2).

La llegada de Allende y la UP al gobierno no trajeron consigo un inmediato planteamiento de la modificación de las estructuras estatales. La nueva administración comenzó a aplicar su programa de cambios tales como conformar un Área de Propiedad Social, incrementar la presencia del Estado en la actividad económica adquiriendo $-\mathrm{y} / \mathrm{o}$ expropiando- grandes industrias, bancos y empresas, nacionalizando la gran minería del cobre, estableciendo medidas redistributivas e incrementando los salarios. Otras acciones de la hora inicial consistieron en proceder a indultar a personas investigadas por delitos tales como usurpación de tierras, asaltos bancarios y organización de guerrillas (Díaz 2014). Pese al clima de división política que se generó en el país, el primer año de gobierno fue el mejor si nos atenemos a los resultados económicos que exhibió: el PIB subió al $8 \%$; la inflación bajó al 22,1\%; el desempleo cayó al $3,8 \%$; y el aumento de los salarios trepó al $22,3 \%$, y ello por mencionar solo algunos de los indicadores más positivos (Meller 1996; Correa et al. 2001). Además, el oficialismo alcanzó el $49,73 \%$ de la votación, contra el $26,1 \%$ de la DC y el $21,95 \%$ de la derecha en las elecciones municipales de 1971 (Díaz y Valdés 2015b).

Entre los cambios institucionales propuestos, el ejecutivo presentó el 14 de noviembre de ese año, un proyecto de reforma constitucional para establecer un congreso unicameral. En poco tiempo la oposición asoció el proyecto con el "totalitarismo marxista" y una estructura de Estado tendiente al "partido único". Pese a todo, dicha iniciativa fue vista por gran parte del oficialismo como una mala opción para solicitar el arbitraje del electorado en los temas más importantes. Los propios partidos de la UP terminaron pidiendo a Allende que retirara la urgencia del proyecto; lo cual se materializó el 1 de diciembre de 1971 (J. Garcés 1990). Aunque la principal razón de tal decisión radicó, más bien, en el hecho de carecer de una mayoría parlamentaria suficiente como para emprender una empresa de esta envergadura (Bandeira 2008).

En todo caso el debate prosiguió al interior de la izquierda con respecto a cómo hacer la revolución y cómo llevar a cabo el proceso de transformaciones estructurales en el país. En sus memorias, Luis Corvalán señalaba que "no existió nunca un criterio uniforme sobre el carácter mismo de la revolución y de cómo conducir el proceso de cambios" (Corvalán 1997:168). Para los socialistas resultaba fundamental la conformación de un Poder Popular que impulsara desde las bases la revolución socialista de forma paralela y alternativa a ese oficialismo que se encontraba instalado en La Moneda. Desde 1971 el PS planteaba que las organizaciones sindicales y populares debían irse incorporando al ejercicio del poder real no solo al interior del Estado sino también conformando otras estructuras que culminasen "en la Asamblea del Pueblo" en pos del socialismo (Farías 2000: 621-622). A diferencia de la mirada y el análisis de los comunistas, para quienes la formación de ese Poder Popular debía tener como objetivo fortalecer el gobierno allendista y no plantearse como una alternativa a su gestión; ya que esto último tendería a debilitarlo (Monsálvez 2006). Por otro lado, el PC esperaba que las 
transformaciones económicas ampliaran los apoyos sociales al gobierno (Gaudichaud 2016).

El MIR, por su parte planteaba,

\begin{abstract}
"la construcción de una Fuerza Social Revolucionaria, consciente de la inevitabilidad del enfrentamiento armado, que fuera capaz de crear una nueva situación política y, a partir de ello, la construcción de una nueva legalidad, como único camino para resolver el problema del poder. De esta manera, la consigna del Poder Popular adquirió una dimensión estratégica, en cuanto cristalizó como una manifestación paralela al Estado burgués, asentado en las organizaciones y fuerzas sociales autónomas del proletariado y el pueblo" (Goicovic 2016: 121).
\end{abstract}

De modo que desde fines de 1971 el MIR reivindicó con energía la tesis del Poder Popular, teóricamente compartida por otros sectores de la izquierda:

"Un análisis de la declaración de principios del Frente de Trabajadores revolucionarios (FTR) - frente sindical del MIR - permite darse cuenta que, a esta fecha (diciembre de 1971), el discurso sobre el «Poder Popular» ya había sido ampliamente desarrollado. Otras investigaciones muestran más bien una continuidad en la política del MIR sin qu se puedan identificar verdaderos 'giros teóricos' durante el periodo 1970 - 1973, aunque confirma que sólo a partir de 1972, los miristas concentrarán su política en torno a la reivindicación del poder popular" (Gaudichaud 2016: 103).

En suma:

"[Unos] han puesto el énfasis en la autonomía popular y en proposiciones de tipo corporativo o societario; $y$, por otra parte, [otros han privilegiado] aquellas orientaciones que han subrayado la necesidad de participar del Estado para realizar desde allí la reforma del orden social". (Garcés 1994:262).

Hacer la revolución significaba transformar el régimen político social y económico empapado de capitalismo dependiente, cambiándolo por un modelo socialista donde no hubiera explotadores ni explotados; donde se distri- buyera la riqueza colectivamente; y en el cual primaran los principios de solidaridad y justicia social sobre los del individualismo competitivo. Teóricamente ello implicaba apoyarse en el pensamiento marxista-leninista (Pinto 2005). Suscribirlo, involucraba desarrollar una política activa, combatiente, destinada a transformar la sociedad. De esta forma, los verdaderos revolucionarios combatían a los defensores de la democracia "burguesa" y se oponían a los anarquistas y los sectores reformistas. Pero, ¿Quiénes eran los reformistas? Para muchos, sin duda, los integrantes del Partido Comunista (Monsálvez 2006).

En la idea de romper violentamente con la institucionalidad "burguesa" y "capitalista" de Chile -según se afirmaba en aquella épocaconfluyeron gran parte del PS, el Movimiento de Acción Popular Unitaria (MAPU) dirigido por Oscar Guillermo Garretón, la Izquierda Cristiana (IC) conducida por Bosco Parra, y el Movimiento de Izquierda Revolucionaria (MIR), para el cual el camino al poder era el de las armas, con un enfrentamiento que se estimó como inevitable. Efectivamente, la izquierda revolucionaria buscó "radicalizar la movilización popular con el objeto de "saltar» de la fase democrática a una fase decididamente socialista del proceso chileno" (Garcés 1994: 26); además, el Estado «burgués» nunca permitiría un cambio de esta naturaleza. Pero, para otros sectores de izquierda, aún no estaban dadas todas las condiciones necesarias para romper la institucionalidad vigente y hacerse violentamente con la totalidad del poder. En esta última perspectiva se encontraba el PC, el Partido Radical y el propio Allende (Monsálvez 2006). La revolución debía realizarse gradualmente y sin vulnerar el Estado de derecho, siendo esto último -además- un compromiso contraído por el propio Salvador 
Allende cuando recibió el apoyo demócratacristiano para ser investido presidente por el Congreso Pleno. Los gradualistas recibieron el calificativo de «reformistas»; y los revolucionarios partidarios de la insurrección de las masas fueron tildados con el epíteto de «extremistas».

De manera que, en el segundo año de gobierno, la izquierda partidaria de acelerar el proceso revolucionario comenzó a impulsar una organización popular que edificara un poder alternativo a la institucionalidad conducida en ese momento por el gobierno de Allende. Esa propuesta -la Asamblea del Pueblo- surgiría en Concepción, toda una novedad en un país de fuerte centralismo político; sin embargo, no fue el producto del azar. En la elección presidencial de 1970, Allende logró el 48,3\% de votos en la provincia de Concepción, el 74 y el $64,3 \%$ en las comunas minero carboníferas de Lota y Coronel, respectivamente; el $48 \%$ en el Departamento de Talcahuano, donde se concentraban los sectores obreros del acero, la refinería de petróleo y la industria metal mecánica; el $52 \%$ en la subdelegación de Chiguayante, donde habitaba una relevante población obrero textil; y, el $56 \%$ de los votos válidamente emitidos en Penco, comuna donde los sectores laborales locero y azucarero eran importantes (ES 5.09.1970; ES, 5.09.1970; y ES, 6.09.1970). En la citada capital penquista, en la elección presidencial, Allende había alcanzado el $37,2 \%$ de los sufragios. En las elecciones municipales de 1971, el respaldo electoral a la izquierda se elevó a un 56,09\% (Díaz y Valdés 2015b). De forma tal que el oficialismo tenía en el Gran Concepción un soporte social que descansaba en importantes sectores laborales vinculados a la actividad industrial llevada a cabo en Concepción y Talcahuano, pero también en Penco, Tomé y Chiguayante, Coronel y Lota, cuyas características ya se han mencionado.

Veamos la coyuntura desde donde surgió la convocatoria a la Asamblea del Pueblo. A mediados de 1972 nuevas discrepancias políticas afloraron al interior de la UP, esta vez en Concepción. Allí, el PC se negó a participar del Ilamado oficialista hecho por el Comité Político de la UP, el cual convocó "a todos los sectores progresistas" a realizar una marcha y "tomarse" las calles el viernes 12 de mayo. La izquierda consideraba que la calle le pertenecía y no podía dejar que fuera ocupada por un acto masivo de la oposición, bajo el lema Marcha de la Democracia, anunciada para realizarse ese mismo día. La oposición venía realizando actos similares desde el mes de abril, en un intento de demostrar que ella también tenía una capacidad de convocatoria masiva capaz de ocupar calles y plazas. La coalición de gobierno intentó contrarrestar el acto que los partidos de esa oposición "reaccionaria" e "imperialista" pretendían realizar. Este había sido convocado por los cuatro presidentes locales de los partidos opositores: Hosaín Sabag (Partido Demócrata Cristiano); Juan Eduardo King (Partido Nacional); Agustín Mosso (Democracia Radical); y, Osvaldo Briones (Partido Democrático Nacional), sumándose también, aunque no oficialmente, los integrantes de Patria y Libertad (PyL 11, 1972: 9; ES 26.05.1972:1). Ambas marchas fueron autorizadas por Vladimir Lenin Chávez, el intendente comunista de la provincia (EDC 06.05.1972).

El mitin de la oposición debió llevarse a cabo en calle Los Carrera, entre Aníbal Pinto y Tucapel; el de la UP (sin el PC) en Aníbal Pinto con O'Higgins. A ésta se sumaría la marcha del Frente de Trabajadores Revolucionarios (FTR) 
y el Movimiento de Izquierda Revolucionaria (MIR), autorizados para reunirse en la Plaza Perú. En este escenario, un enfrentamiento entre las izquierdas y la oposición se evidenciaba como probable; ello motivó al gobierno nacional a solicitar la suspensión -y aplazamiento- de las marchas de la izquierda (ES 13.05.1972).

No obstante, diversos sectores de la izquierda se reunieron el día 12 en el foro de la Universidad de Concepción, desde donde enfilaron al centro de la ciudad, produciéndose algunos incidentes con simpatizantes de la oposición, arrojando un saldo de 40 heridos (10 hospitalizados: 5 graves y 5 en observación). A ello habría que sumarle el fallecimiento de un estudiante: Eladio Caamaño Sobarzo; víctima de la disolución de manifestantes de izquierda por parte de Carabineros de Chile (PF 23.05.1972). Este hecho trajo como consecuencia que los partidos de la UP (menos el PC) y el MIR pidieran la destitución del intendente Chávez (ES 14.05.1972). Además, todo esto dio lugar a que dichos sectores de la izquierda manifestaran que existían dos políticas de transformación social: una, que olvidaba la lucha de clases y se apoyaba solo en el Estado para hacer simples cambios reformistas en el país, aludiendo expresamente al PC; y otra, que no aceptaba la conciliación con los enemigos del pueblo y que buscaba apoyarse en la movilización de las masas para realizar las radicales y necesarias transformaciones estructurales demandadas. Al respecto, los comunistas respondieron que "cualquier intento de presentar otra alternativa política que no sea la Unidad Popular y su programa" era "contrarrevolucionaria", porque a la larga favorecería solo "a los enemigos del pueblo", conduciendo todo lo alcanzado "al despeñadero" (EDC 24.05.1972:13; EDC 26.05.1972:8).
Cabe mencionar que después de la Marcha de la Democracia realizada, finalmente, por la oposición en Concepción el 24 de mayo, el PN declaraba a la prensa que con ese acto masivo la UP nunca más volvería a decir que la calle le pertenecía (C 26.05.1972).

Es en este contexto donde las izquierdas en Concepción, considerando su importancia en la provincia, comenzaron a impulsar una alternativa política para compartirla con el conjunto del país. Casi todos los partidos de la UP y el MIR planearon un avance y profundización en la práctica del poder organizado de sus diversas bases políticas. Para el MIR, por indicar un caso, la consigna del Poder Popular era importante porque de concretarse se constituiría "como una manifestación paralela al Estado burgués, asentado en las organizaciones y fuerzas sociales autónomas del proletariado y el pueblo" (Goicovic 2012: 167).

En esos momentos, para el MIR chileno, eran muy importantes los hechos acontecidos en Bolivia, con ocasión de la experiencia efectiva de una Asamblea Popular impulsada por sectores de la extrema-izquierda disconformes con la política del presidente Juan José Torres. Para referirnos a ella debemos remontarnos al 12 de febrero de 1971, cuando el Comando Político de la Central Obrera Boliviana (COB) aprobaba las bases para su instalación el $1^{\circ}$ de mayo, coincidiendo con los actos del Día del Trabajo; aunque su instalación efectiva tendría lugar el 22 de junio, cuando se elaboraba su reglamento y los temas administrativos de su puesta en marcha.

La Asamblea estuvo integrada por 208 representantes de diversos organismos sindicales, del pequeño comercio, trabajadores 
cualificados, periodistas, institutos profesionales, artistas, escritores y universitarios. En ella los partidos solo sentaron a 13 representantes del Partido Revolucionario de la Izquierda Nacional, Partido Comunista de Bolivia, Partido Obrero Revolucionario (POR), Partido Comunista (Marxista-Leninista), y del embrionario Movimiento de Izquierda Revolucionario boliviano (MIR) a través del Partido Demócrata Cristiano Revolucionario y el Movimiento Revolucionario ESPARTACO. Quedaron fuera de la misma el Movimiento Nacional Revolucionario, el Partido Demócrata Cristiano y la denominada Falange Socialista Boliviana de Izquierda, liderada por David Añez Pedraza y Walter Vásquez Michel.

La citada Asamblea eligió a Juan Lechín, el mítico líder del movimiento obrero, como su presidente, adoptando las siguientes medidas: 1. Contra un posible golpe fascista, a partir de un proyecto presentado por Guillermo Lora, se planteaba declarar la huelga general con ocupación de fábricas y minas y la formación de un comité de la Asamblea (Comité de Milicias y Tribunales Populares) que asumiera la dirección política militar de la lucha. 2. Se aprobaba una resolución que establecía la cogestión en las minas con elección de los gerentes por los trabajadores. 3. Se planteaba la Universidad única bajo la dirección hegemónica del proletariado, siguiendo el ejemplo de la Universidad de Potosí, cuya dirección estaba compuesta por 19 delegados obreros, 9 estudiantiles y 9 docentes. El 2 de julio se clausuraron sus sesiones acordando volver a funcionar dos meses más tarde. (Lora 1972; Mercado 1974; Strengers 1991; Encinas 1996). Pero, el golpe de Estado del 21 de agosto de 1971 encabezado por Hugo Banzer puso fin al gobierno de Torres y terminó con el experimento que llevó a Le Monde Diplomatique a hablar del surgimiento del "primer soviet de América Latina", el equivalente de los Consejos obreros, campesinos y de soldados que llevaron al triunfo de la Revolución Rusa (Ferreira 2005).

El sueño de esta experiencia boliviana fue observado en Chile por la revista del MIR, obteniendo la conclusión de que solo las masas obreras, campesinas, estudiantiles y pequeño burguesas radicalizadas, "bajo la conducción del proletariado" podían asumir la lucha por conquistar el poder:

\footnotetext{
"La Asamblea del Pueblo, constituida a contracorriente del gobierno de Torres, recoge toda la larga experiencia que las masas bolivianas hicieron a partir de 1952 y expresa su compresión creciente del hecho de que sólo la alianza de obreros, campesinos y pequeña burguesía radicalizada, bajo la conducción del proletariado, puede asumir la lucha por la conquista del poder...Por otra parte, la línea revolucionaria de la mayoría de las Asambleas que plantea constituir a esta en un embrión de poder obrero-campesino, en un instrumento de la lucha de clases que solo puede apoyarse en las luchas de las masas explotadas de la ciudad y del campo, luchas que vayan configurando una real alternativa del poder" ( $P F$ 14.09.1971: 5-6).
}

Claramente, el MIR le planteaba al gobierno de la UP la disputa de la conducción del proceso político chileno:

\footnotetext{
"Esa disputa... desde mediados de año [1972] tomará nuevas formas ante el surgimiento de órganos que daban cuenta de la maduración del movimiento popular y del protagonismo en el proceso: los Cordones Industriales y Coordinadores Comunales de Trabajadores, las dos principales expresiones de lo que se conocería como el Poder Popular" (Leiva 2010: 62-63).
}

En Santiago y Valparaíso existieron embriones de ese Poder Popular a destacar. En Arica, Constitución, Osorno y Punta Arenas hubo al menos una coordinación importante de trabajadores (Gaudichaud 2016). Pero fue en Concepción donde surgió la reunión política 
que implicaba un cierto desafío que el Gobierno debió salir a responder.

Lo cierto es que casi toda la UP y el MIR convocaron para el jueves 27 de julio de 1972, a las 18:00 horas, a una "Asamblea del Pueblo"; evento a realizarse en la Casa del Deporte de la Universidad de Concepción; pero realizado finalmente en el Teatro Concepción, frente a la Plaza Independencia, en pleno corazón de la ciudad (Monsálvez 2006). Los convocantes -PS, MAPU, IC y el Partido Radical- más el MIR, invitaban a "discutir, analizar y denunciar, directa y democráticamente, la función y carácter contrarrevolucionario" del Congreso y el poder Judicial, entre otros (Monsálvez 2006: 46). Otras formaciones integrantes de la UP, como la Acción Popular Independiente y el PC, no participaron de esta convocatoria, rechazando de pleno su constitución (LD 14.08.1972: 5).

Por otro lado, cabe aclarar que desde la asunción del gobierno hasta la realización de la asamblea en cuestión, la oposición de derecha -y en algunos casos con ayuda de la Democracia Cristiana- ya había acusado a cinco ministros de Allende por apartarse del acatamiento de las leyes; y el día de la realización de la citada asamblea se declararía culpable y destituiría al Ministro del Interior (el socialista Hernán del Canto) por no cumplir con la mantención del orden público, contrabando y detenciones arbitrarias de periodistas ( $T$ 28.07.1972; EDC 28.07.1972).

El PC, mediante Mario Benavente, integrante de su Comité Central, aludió al hecho de que "aún no están dadas las condiciones para la constitución de este tipo de asambleas"; asegurando que la citada reunión obedecía a "una maniobra que la reacción y el imperialismo están impulsando, valiéndose de elementos de ultraizquierda y en particular del MIR con su rama el FTR" (EDC 25.07.1972: 5). Esta idea de una asamblea popular era divisionista, extremista y tendía a crear confusión tanto en la UP como en los trabajadores (Monsálvez 2006). Los comunistas reconocían que la susodicha asamblea estaba en el programa de 1970 , pero no se encontraba entre las iniciales 40 medidas de gobierno. Precisaban, además, que para concretar su establecimiento se debía abrir un proceso de reforma constitucional que contemplase su institucionalización (Ibid.).

En cambio, para Manuel Rodríguez (PS) -regidor en la municipalidad de Concepción y presidente en 1972 de la Federación de Estudiantes de la universidad penquista- la asamblea tendría la tarea de "desconocer la representatividad que tiene el Parlamento respecto de los trabajadores"; era "una instancia democrática de revolución" y "una reunión representativa de todos los organismos de lucha de los trabajadores, estudiantes, pequeños industriales y comerciantes" (ES 26.07.1972: 1).

Para los sectores penquistas del MIR la asamblea convocada era "popular y democrática", para impulsar también los "consejos comunales de trabajadores". Era un poder que se oponía

\footnotetext{
"de la única forma posible, al poder que la burguesía mantiene en el poder Judicial, en la burocracia y principalmente en el Parlamento. Es en ese Parlamento donde todas las iniciativas que busquen favorecer a las masas serán sepultadas una a una. Es en ese Parlamento donde se yergue el principal poder del imperialismo y la reacción" (Ibid.: 6).
}

Además, frente al rechazo comunista de la convocatoria, el MIR llamaba a los dirigentes del PC a no alienarse con "los sirvientes políticos de los patrones"; llamando a los "compañeros 
comunistas... a no aislarse de las masas ni del proceso en esta hora crucial" (Ibid.).

El MAPU mediante una declaración interpretó el llamado a la asamblea como una manera "justa" de "integrarse y movilizarse resueltamente a favor del Gobierno Popular y del proceso revolucionario chileno". Este proceso debía desarrollarse mediante la movilización y la lucha del pueblo. "Sólo en esta perspectiva... puede entenderse el inevitable e indispensable proceso de construcción del poder alternativo de las masas obreras y populares frente al poder de la burguesía" (ES 25.07.1972:14).

Los únicos que invocaron -en ese momentoel programa de la UP fueron Humberto Bravo, presidente local del PR, e Iván Arriagada, dirigente de la Juventud Radical Revolucionaria (JRR); quienes afirmaron:

"las asambleas populares están contempladas en el Programa Básico de Gobierno de la Unidad Popular y ... como Partido Radical... apoyamos hoy las asambleas populares y toda otra medida tendiente al logro de los cambios estructurales que el país exige" (ES 26.07.1972: 6).

Hasta la Universidad de Concepción, a través de su Consejo Superior, solidarizó con la Asamblea del Pueblo, considerándola una instancia de apoyo al gobierno (ES 27.07.1972). El 26 de julio, el citado organismo universitario, presidido por el vicerrector $-\mathrm{y}$, en ese momento rector subrogante- Galo Gómez (PS), emitió la siguiente declaración:

"teniendo presente que el día 26 de julio, fecha aniversario del Asalto al Cuartel Moncada, representa el inicio de la lucha liberadora de los pueblos de América, y que, en la realidad histórica que vive nuestro país, esa fecha tiene una importancia trascendente, desde que el mismo anhelo liberador es el que motiva toda la acción del Gobierno popular. Acuerda:1.- Reiterar al pueblo y Gobierno cubanos, el saludo y respaldo de la comunidad universitaria de la Universidad de Concepción en este día tan significativo, en que se conmemora el $19^{\circ}$ aniversario de la gesta de Moncada, y 2.- Declarar que la Universidad de Concepción solidariza con todos los movimientos de masas que se realicen en nuestro país - como es el caso de la Asamblea del Pueblo, a verificarse en el día de mañana en Concepción - que tengan por objeto prestar su apoyo al Gobierno Popular, cuyo accionar está inspirado en la misma idea liberadora de la gesta cubana" (C 27.07.1972:2).

Por su parte, y desde la derecha, el PN penquista consideró la convocatoria a la Asamblea del Pueblo como un intento de los "dirigentes marxistas" de concretar una de las propuestas programáticas de la UP. Pero a juicio de los nacionales, tales asambleas carecían de eficacia legal toda vez que no estaban contempladas en la Constitución del Estado:

\begin{abstract}
"de nada les servirá constituirlas. Nada se acordará válidamente allí, y nada podrán hacer cumplir, desde que nadie estará obligado a obedecerlas. Se trata simplemente de otra pantomima más de los fracasados dirigentes marxistas que, incapaces de dar soluciones efectivas a los problemas colectivos del pueblo, se dedican a estas maniobras para distraer a la opinión pública" (ES 25.07.1972: 14).
\end{abstract}

\section{La Asamblea del Pueblo: llamado revolucionario y reacciones políticas}

El 26 de julio, a las 20 horas se reunieron los representantes de los partidos y movimientos políticos convocantes a la Asamblea del Pueblo; al evento también concurrieron otras 143 organizaciones: 61 sindicatos, 6 consejos campesinos, 32 campamentos de pobladores urbanos, 17 organizaciones estudiantiles y 27 centros de madres (ES 27.07.1972). Unos 30 oradores hicieron uso de la palabra (EDC 28.07.1972). Según un testigo de la época, unas seis mil personas asistieron a esta reunión, contabilizando tanto aquellas que se 
encontraban al interior del Teatro Concepción, como aquellas otras que debieron situarse en la Plaza de la Independencia, debido a que el reducido aforo del citado local no pudo cobijar a todos los concurrentes (PF 15.08.1972). Hubo parlantes en el exterior del recinto por los cuales se pudo escuchar a quienes hicieron uso de la palabra (C 28.07.1972).

En la convocatoria se hizo presente por parte de los oradores la crítica a la institucionalidad vigente y la necesidad de hacer realidad nuevas formas de participación y representación popular. Quizá la moción más importante fue la de Eduardo Aquevedo, dirigente nacional e integrante de la comisión política del MAPU, quien señaló: "ninguna acción parlamentaria o de cualquier índole será acatada, si pretende devolver cualquiera de las conquistas logradas" (en clara referencia a la toma de predios y a las industrias adquiridas por el Estado o traspasadas al área de propiedad social por decreto presidencial). Además, se refirió a la necesidad de organizar a las masas para defender las industrias y los fundos en manos de los trabajadores; para lo cual se debían adoptar "las formas de lucha que sean necesarias" (ES 28.07.1972: 7), apoyándose en los partidos de izquierda y evitando el sectarismo; alusión al PC que no compartía las preocupaciones de la citada asamblea. Este sería el punto de vista moderado en la reunión. Tras los diversos discursos, el voto de los partidos de la UP presentes indicó lo siguiente:

"La Asamblea del Pueblo acuerda en primer lugar rendir un homenaje a la heroica revolución cubana. Acordamos repudiar y denunciar al Parlamento, por ser dirigido por los enemigos del pueblo, que están abocados a paralizar el proceso revolucionario, llegando al extremo de devolver las industrias expropiadas a sus antiguos propietarios. El pueblo de Concepción no aceptará que el proceso vuelva atrás. Las industrias o fundos expropiados no volverán a manos de los patrones. Esta asamblea acuerda un apoyo al proceso revolucionario a través de todos sus organismos de masas, tales como las Juntas de Abastecimientos y Precios, las Juntas de Vecinos, los Centros de Madres. Nosotros insistimos en las asambleas de masas" (C 28.07.1972: 3).

Por otra parte, el MIR propuso "la disolución del Parlamento y la creación en su lugar de una Asamblea del Pueblo", además de un paro nacional para protestar en contra de "la mayoría reaccionaria del parlamento que pretende aprobar proyectos que significan devolver fábricas a los explotadores y detener los avances de los trabajadores" (Ibid.); punto de vista que correspondería a una visión más extrema, la cual fue acompañada por la consabida consigna de "Pueblo, conciencia, fusil... MIR, MIR” (QP 3.08.1972: 9).

El punto en el cual coincidieron los representantes de la UP y el MIR fue en que "el pueblo de Concepción" no aceptaría que el proceso de expropiaciones retrocediera: "Las industrias o fundos expropiados no volverán a manos de los patrones". Con un vocabulario diferente, coincidieron también en crear asambleas de trabajadores. EI MIR las veía necesarias en cada comuna y la UP insistía en las asambleas de masas (EM 29.07.1972: 1 y 16).

Sin perjuicio de lo anterior, hasta comunidades de base cristianas apoyaron a la Asamblea del Pueblo. Fue el caso del grupo de estudiantes que se reunían en la Parroquia Universitaria; un local situado en calle Los Olmos 1255. En las cercanías del barrio universitario. Ellos declararon que esperaban que "el pueblo" derrumbara a los opresores y que construyera "la fraternidad humana que Cristo vino a predicar". Para ello anunciaron que seguirían luchando junto a ese pueblo que exigía en la referida asamblea la 
constitución de Consejos Comunales, Consejos Campesinos, expropiaciones y la liberación de los oprimidos (PF 15.08.1972: 13).

En esos momentos los concurrentes a esa reunión asamblearia, especialmente los socialistas, pensaron en llevar a cabo otros cónclaves similares en el corto plazo (C 2.08.1972); acordando llevar a cabo una segunda reunión de la citada Asamblea el 24 de agosto, pero ello nunca ocurrió (EM 29.07.1972). Sin embargo, es posible pensar que con las críticas de Allende y las discusiones políticas posteriores no existió el ambiente necesario como para reproducir dicho experimento, ni en Concepción ni en ninguna otra parte del país. En este mismo sentido el MAPU, por intermediación de Juan de Dios Fuentes, su secretario regional, señaló, tras conversar con Jaime Gazmuri (secretario general del partido) y con Oscar Garretón (integrante de la comisión política) que no participaría en otras asambleas similares. De este modo los mapucistas acataron el pleno partidario realizado en Santiago, donde se había acordado desarrollar el Poder Popular, pero solo al interior de las organizaciones surgidas desde el seno del gobierno allendista, como las Juntas de Abastecimientos y Precios (JAP), o bien desde organizaciones existentes con anterioridad, señalando directamente a la Central Única de Trabajadores: "estamos completamente de acuerdo con la dirección nacional del partido en el sentido de que el nombre de Asamblea Popular tiende a confundir a las masas y a los partidos de la Unidad Popular" (ES 9.08.1972: 6).

Solamente en el PS, en la IC y en la Juventud Radical Revolucionaria, se prosiguió apoyando la tesis de la Asamblea del Pueblo de Concepción; aún después del rechazo que Allende opusiera a tal instancia (PF 15.08.1972; C 3.08.1972; C
9.08.1972). Pero había matices: en la sección penquista de la IC se indicó que no se pensaba que dicha asamblea conformara un poder paralelo al gobierno, sino que la asamblea tendía a dar apoyo revolucionario al gobierno (ES 2.08.1972). EI PS insistió en rechazar la imagen de que la Asamblea del Pueblo fuera un poder paralelo al Congreso o al Poder Ejecutivo; no obstante, hubo puntos de vista en el partido, como el de Guaraní Pereda Da Rosa, integrante del Comité Central, según el cual, mediante la organización de las masas se daría solución a sus problemas, en circunstancias de que el Congreso o el Poder Judicial entorpecían las iniciativas del gobierno (Gaudichaud 2016). En cuanto a Miguel Enríquez, secretario general del MIR, declaró que la "Asamblea de Concepción" fue un acto de agitación y propaganda, confirmando su llamado a conformar un Poder Popular autónomo del Estado; en su visión, serían los Consejos Comunales de Trabajadores las bases donde descansaría este nuevo poder alternativo al Parlamento y a la Justicia (Cit. por Gaudichaud 2016).

Ni el gobierno, ni la oposición demócrata cristiana, ni la derecha permanecieron indiferentes a esta Asamblea del Pueblo. Allende la rechazó de plano. Por lo pronto, el 31 de julio el primer mandatario envió una carta a los partidos de la UP fijando una posición crítica. Comenzaba señalando que lo acaecido en Concepción era un hecho "de la más extraordinaria gravedad"; si el gobierno tenía tareas y una estrategia, ello le llevaba a rechazar

\footnotetext{
"cualquier intento de diseñar tácticas paralelas, espontaneístas, so pretexto de que personas o grupos se sientan depositarios de la verdad y persistan en su afán de desviar la marcha del pueblo para colocarlo frente a riesgos en los cuales la vida de los hombres... esté innecesariamente expuesta". (ES 1.08.1972: 12).
} 
El proceso divisionista producido en Concepción -agregaba- solo "sirve a los enemigos de la causa revolucionaria". Había que trabajar duro y ganar las elecciones parlamentarias de 1973; solo una mayoría popular en el Congreso podría "impulsar los cambios constitucionales y legales indispensables para sacar al país del subdesarrollo y acabar con el poder de obstaculizar de una oposición... que ampara los intereses de la reacción". Asimismo, Allende fue claro al enunciar que una convocatoria de ese tipo no emergía del divisionismo político: una Asamblea Popular "auténticamente revolucionaria" concentraba en ella toda la representación del pueblo; en consecuencia, podía deliberar y también "gobernar" (Ibid.). Pero no era este el caso. Pensar en algo así era "absurdo" e irresponsable. El gobierno era uno, estaba "legítimamente constituido" y al "servicio de los trabajadores;" en consecuencia -recalcaba- no iba a tolerar "que nada ni nadie atente contra la plenitud del legítimo gobierno del país". En su carta, además, afirmaba:

\footnotetext{
"Para continuar gobernando al servicio de los trabajadores, es mi deber defender sin fatiga el régimen institucional democrático. $Y$ no concibo que ningún auténtico revolucionario responsable pueda, sensatamente, pretender desconocer en los hechos el sistema institucional que nos rige y del que forma parte el gobierno de la Unidad Popular. Si alguien así lo hiciera no podemos sino considerarlo un contrarrevolucionario. El régimen institucional actual debe ser profundamente cambiado porque ya no se corresponde con la realidad socioeconómica que hemos creado. Pero será cambiado de acuerdo con la voluntad de la mayoría del pueblo, a través de los mecanismos democráticos de expresión pertinentes Está claro que no se ha hecho un examen correcto de la correlación de fuerzas en el país para imponer, por un simple acto de voluntad de algunos apasionados, un instrumento que, en lugar de servir a las masas, las colocará en una situación difícil si los dirigentes de los partidos de la Unidad Popular no rectifican su conducta" (Ibid.).
}

Allende fue duro en sus expresiones: agregó que la asamblea popular penquista era también un "fenómeno artificial", "peligroso" y una "tribuna verbalista". Si fuera un "proceso social auténtico" capaz de impulsar "la lucha del pueblo", éste así lo reconocería; y también sus adversarios, quienes han publicitado su existencia para apartar al pueblo de sus tareas y alejarlo de su Programa. Además, el gobierno estaba diseñando una nueva Constitución política para transitar al socialismo; de forma que había tareas con contenido de las cuales ningún militante de la UP se podría apartar (lbid.).

Fueron también duros con la Asamblea del Pueblo los senadores comunistas Volodia Teitelboim y Jorge Montes. Teitelboim calificó a la referida asamblea como "una idea delirante y calenturienta"; y se preguntaba: "¿qué es lo que se pretende con esto?". Y respondía: "Es la locura, es la repetición de esa asamblea del pueblo de Bolivia, que contribuyó alegremente a derrocar a Juan José Torres". Su colega Montes, por su parte, se refirió a ella en términos similares, al afirmar que ésta "era una lesera", enunciando que era "contrarrevolucionario plantear esto de la Asamblea del Pueblo"; aseverando que "los que suscribieron tal proposición [estaban] siendo llevados por la política divisionista del MIR" (EM 29.07.1972:16; ES 1.08.1972: 7; LD 29.07.1972: 1 y 4$)$.

Sin embargo, quizás el discurso político más hostil en contra del gobierno por su rechazo a la asamblea del pueblo provino del Partido Comunista Bandera Roja (PCBR), alineado con la izquierda más radicalizada y situada fuera de la UP (Lo Chávez 2012). Su planteamiento fue hecho después de un violento allanamiento policial a una población en Lo Hermida -en 
Santiago-, y que dejó un fallecido (René Saravia), varios heridos, arrestos, más el rechazo de los pobladores al proceder del gobierno y de la Policía Civil (PF 29.08.1972, Documentos). Precisamente, uno de los dirigentes del PCBR, Daniel Moore, fue uno de los que encaró a Allende en su visita a la población allanada. Pues bien, en la convocatoria del PCBR para realizar una Asamblea del Pueblo en Santiago -y a marchar hacia el palacio de La Moneda-, se denunciaron crudamente los sucesos acaecidos en la citada población, atacando duramente al gobierno:

\begin{abstract}
"esta matanza fue una provocación montada con el pretexto de atacar a militantes de izquierda, pero en los hechos para crear un clima propenso a la represión obrera y popular. Este gobierno débil, que ha elegido como enemigo al pueblo y en los cuales recibe a los representantes de los monopolios sometiéndose a sus exigencias, ha desatado la violencia contra las masas. Este gobierno necesita mantener el actual estado de cosas, Este gobierno necesita reprimir para poder 'establecer la calma necesaria para llegar a las elecciones de abril (sic) del 73' y así cumplir con las exigencias que pone la Derecha. Todos los de arriba están débiles. No les basta con la farsa de la batalla de la producción, estrujar al pueblo con la ilusión de así poder salvar la crisis, sino que además pretenden descargar la crisis sobre la clase obrera, sus compromisos con el Fondo Monetario Internacional y los monopolios internacionales lo obligan a devaluar la moneda y descargar la inflación afectando el consumo popular. Que lo sucedido confirma el carácter antipopular y antiobrero del gobierno, socialista de palabra y burgués en los hechos (...) y se declara defensor de la institucionalidad burguesa... la farsa de las elecciones... no resuelve ni la crisis ni el desabastecimiento ni las muertes populares. Debemos organizarnos en poder, nuestro poder: popular y revolucionario dirigido por la clase obrera frente a las falsas alternativas ofrecidas por el gobierno reformista de Allende y el Parlamento burgués, en su mayoría proyanqui" (C 9.08.1972: 1).
\end{abstract}

No nos consta que la reunión convocada por el PCBR para el 11 de agosto se realizara, sin embargo, nos da una idea de los puntos de vista existente en una parte menor de una izquierda radicalizada.
En Concepción terminaba el mes de agosto y no había sido posible que se reunieran los dirigentes de los partidos de la UP. Es posible que las relaciones entre los integrantes de la coalición quedaran algo deterioradas tras la polémica a que dio lugar la referida Asamblea del Pueblo del 27 de julio (ES 22.08.1972).

Ahora bien ¿Cuál fue la reacción de la oposición -de derecha y del centro político-frente a la Asamblea del Pueblo? Las primeras reacciones de la derecha se produjeron en Santiago: Pedro Ibáñez -senador del PN-, comentó el documento en el que Allende mostraba su rechazo a la asamblea penquista, tachándolo de ser una verdadera "carta - lamento" que parecía "una especie de testimonio de quiebra". Enseguida agregó:

"el Ejecutivo le quiere emborrachar la perdiz [confundir]
al pueblo. Les dice que no sean violentos en esta etapa,
porque no hay que olvidar en ningún momento que los
marxistas no han abandonado la vía armada para lograr
el control total. Destacados jerarcas comunistas lo
han dicho. El Secretario General del PC, senador Luis
Corvalán... Entonces los comunistas no están por la
violencia, porque ahora no conviene tácticamente" ( $T$,
2.08.1972: 9).

Por su parte, el diputado nacional Mario Arnello replicó la interpretación de la quiebra política. En definitiva -afirmó- la política marxista habría quebrado al gobierno. Éste, contenía en su interior las diferencias que habían aflorado en la Asamblea del Pueblo en Concepción, lo cual traducía la profunda "escisión entre comunistas y socialistas" (QP 17.08.1972: 41). Ahora bien, para el senador radical (por Ñuble, Concepción y Arauco) Humberto Aguirre Doolan, el rechazo del PC y del PN a la Asamblea del Pueblo era repentino, inexplicable y "un curioso contubernio" (Diario de Sesiones del Senado Legislatura Ordinaria, 1.08.1972: 2447). Ello 
no era óbice para que el también senador radical Luis Fernando Luengo se preocupase de señalar que el PR no había respaldado la citada asamblea, contrariamente a lo afirmado por la sección penquista de la Juventud Radical Revolucionaria (Diario de Sesiones del Senado, Legislatura Ordinaria, 10.08.1972).

Considerando la situación política del país en esos momentos, iniciándose agosto, todos los partidos de la oposición emitieron una declaración pública en Santiago enjuiciando duramente al gobierno, acusándolo de actuar usando "tácticas fascistas y totalitarias." Sobre la declaración opositora también editorializó EI Sur de Concepción en dos oportunidades. En su crítica más dura la oposición señaló:

\footnotetext{
"bajo el actual gobierno, ya no existe verdadera democracia, porque sobrepasando el imperio de la Constitución y de la ley, se está conduciendo al país, en forma cada vez más acelerada, hacia una dictadura totalitaria mediante la estatización progresiva de la actividad económica que, fatalmente conduce al control político de la ciudadanía; mediante el ataque permanente a los poderes del Estado, tanto Judicial como Legislativo, y el desconocimiento de las prerrogativas y deberes que les competen; mediante el desprecio a los sectores populares $\mathrm{y}$, particularmente, de los trabajadores, a los que no se toma en cuenta para decidir sobre el destino de las actividades en que laboran y mediante la persecución, la prepotencia y el sectarismo que evidencian los personeros de Gobierno" ( $T$, 4.08.1972: 15)
}

Aunque la declaración opositora no enfocó su análisis en la asamblea popular realizada en Concepción, aludió a las diferencias de método político que afectaba a la izquierda; indicaba que socialistas y comunistas compartirían "una misma meta": establecer "una dictadura totalitaria", advirtiéndose "contradicciones internas... en la combinación oficialista [en relación] con los medios para llegar... a esa misma meta" (Ibid.); pero imponiéndose el criterio comunista que hiciera suyo Allende en su carta de rechazo a la asamblea popular penquista. Finalmente, para encarar la situación política, la oposición anunció su decisión de "concertar acciones comunes, especialmente en el orden legislativo... y de enfrentar confederados las próximas elecciones [parlamentarias] de marzo de 1973" (Ibid.). Poco después, terminando el mes, el PN declaró que el país vivía un "proceso de decadencia histórico", en el cual el partido notificaba que opondría "la justicia a la anarquía, la razón a la sinrazón y la violencia a la violencia" (ES 21.08.1972: 16).

En estas circunstancias, especialmente frente a las propuestas de la Asamblea del Pueblo, en la capital penquista no se registraron muchas reacciones políticas por parte de la oposición. El Partido Nacional no se pronunció directamente acerca de esa reunión; en verdad estaba más ocupado en definir los cuatro candidatos que presentaría en la elección parlamentaria del marzo próximo (ES, 6.08.1972). Pero la Democracia Cristiana fue más locuaz y emitió una declaración en la cual afirmó que la citada asamblea era "sediciosa", "transgredía" la Constitución, no tenía valor legal alguno; y, atentaba en contra de la soberanía nacional, la cual se expresaba "a través de las mayorías y no por medio de choclones politiqueros o dirigentes sin representación" (C 27.07.1972: 2). Cabe señalar que la sección local del PDC se preocupó por aclarar a la ciudadanía que, si bien era un partido antagónico al gobierno, era distinto doctrinariamente a la derecha y a la ultraderecha, con quienes estaba -por estrategia- "circunstancialmente en una misma situación opositora", según declaraba Pablo Estrada Roa, recién electo presidente provincial de la formación falangista (C 1.08.1972: 3). 
Se podría recordar, tal y como la reciente historiografía ha tratado de resaltar, el papel protagónico que cobró las mujeres de oposición a la UP, más allá de las actuaciones de los partidos políticos, sobre todo a raíz de la connotada marcha de las cacerolas vacías del 1 de diciembre de 1971 en Santiago (Power 2008). A raíz de esta marcha organizada por el Ilamado Poder Femenino se organizó un movimiento conocido como Sol, el acrónimo de Solidaridad, Orden y Libertad, y que comenzaría a organizarse en Concepción a comienzos del año 1972, desplazándose a la zona el senador Francisco Bulnes (PN) quien declaró que dicha formación estaría destinada a "producir un contacto con las distintas fuerzas democráticas, especialmente entre las mujeres" (ES 11.03.1972:8; EDC, 11.03.1972: 5). Esta organización nutriría muchas de las protestas políticas delaoposición, después delarealización de la Asamblea del Pueblo, especialmente en lo referente a la constitución de las JAP (Juntas de Abastecimiento y Control de Precios), apoyando además el paro de los transportistas en octubre (Díaz 2015; ES, 14.10.1972). Claro está que no puede desdeñarse, ni desconocer, el papel de las mujeres adscritas a la UP, quienes desfilaron condenando aquella manifestación, santiaguina del 1 de diciembre, y a la cual el PC de Talcahuano calificó como abiertamente sediciosa (EDC 9.12.1971; ES, 16.12.1971; $E D C, 16.12 .1971)$.

Después de esta asamblea, el PN penquista acordó impulsar diversas formas de protesta en contra del Ejecutivo; se trató de las Marchas del Hambre. La DC también promovió sus propias manifestaciones públicas. Motivos no faltaron, especialmente la inflación existente (162,38\% en diciembre), además del desabastecimiento de productos, la continuación de las ocupaciones de predios y la intervención de empresas y fábricas por parte del gobierno (ES 22.08.1972).

Preparando la marcha del 30 de agosto, los nacionales expresaron en Concepción: "Los nacionales no podemos acallar nuestra voz cuando ha llegado el momento de protestar contra la ola de alzas [de precios] que ha decretado el gobierno", dijo Juan Eduardo King, presidente local del PN. El gobierno -agregóera una gestión fracasada, por lo cual había que protestar y, "dar la cara en la lucha en contra de los ineptos que pretenden llevarnos a la miseria y a la esclavitud". La marcha del día 30 sería protagonizada por los integrantes de la Confederación Democrática; aunque para ese día no tendría autorización por parte del intendente penquista (ES 27.08.1972:12; ES 28.08.1972: 5). Hecho que motivó una agria declaración del PN, indicando que éste actuaba en forma "sectaria y anticonstitucional", por coartar "la libertad de expresión" y atropellar "las garantías constitucionales" (C 30.08.1972: 3). Pese a todo, estudiantes de oposición igual salieron a la calle a manifestarse, principalmente del PDC. Hubo violentos incidentes entre manifestantes de la oposición y del gobierno en el cruce de la calle Barros Arana con Aníbal Pinto, lo cual motivó la intervención de Carabineros para disolver los grupos y evitar males mayores (C 31.08.1972).

Posteriormente al surgimiento de la Asamblea del Pueblo, y a su rechazo por el gobierno y por la oposición, sobrevendrían otros hechos donde proseguiría produciéndose el distanciamiento político entre el gobierno con pretensiones revolucionarias y la oposición que invocaba el sistema político existente como una estructura de convivencia democrática en la cual no cabía introducir cambios para establecer un sistema socialista. El desencuentro político chileno 
dio lugar a una crisis de convivencia que fue finalmente superada violentamente por medio del Golpe de Estado, el cual en Concepción -a diferencia de Santiago- se impuso sin mayores dificultades (Monsálvez 2014). Pese a ello hubo algunos núcleos de una inicial e inútil resistencia. Esto aconteció cuando en el centro de Concepción, algunos francotiradores opusieron resistencia, desde el Hotel Alonso de Ercilla, a los militares que allanaban varios inmuebles en busca de dirigentes del destituido gobierno. Hubo acciones similares en la secretaría del MAPU y en el edificio de Radio El Sur. (ES 13IX-1973; EDC, 13-IX-1973). Funcionarios de carabineros realizaron una intensa labor de patrullaje en la capital penquista y en todas las localidades vecinas a Concepción; manteniendo una estrecha vigilancia en todos los sectores mientras se prolongaba el toque de queda impuesto en todo el país y que en la zona se extendía desde las 21 horas hasta las 6 horas de la mañana (EDC 15-IX-73). A dos días del golpe el general-intendente Washington Carrasco emitió una declaración con relación a los cerca de 200 detenidos en aquellas primeras horas: "Me es absolutamente necesario dirigirme nuevamente a la ciudadanía para explicar cuál es la situación de aquellas personas que por seguridad han debido ser detenidas. Me adelanto a decirles, bajo mi palabra de honor, de que todos, absolutamente todos los detenidos, han sido tratados en la forma humana que corresponde y que se encuentran sin novedad y en perfectas condiciones en la Isla Quiriquina" (EDC 14-IX-1973: 6).

\section{Conclusiones}

La Ilamada Asamblea del Pueblo realizada en Concepción y convocada por los partidos de la UP menos el Partido Comunista, fue una manifestación política de dirigentes y bases -en ese orden- que propuso el reemplazo del Congreso por una asamblea popular, porque consideraba que el Parlamento -con su accionar apegado a la Constitución y a las leyes-, impedía el avance de las transformaciones revolucionarias que impulsaba la izquierda deseosa de incrementar la velocidad con la cual implantar el socialismo. Aunque las propuestas emanadas de dicha asamblea no llegaron a permear el gobierno, el cual rechazó de plano la Asamblea del Pueblo, la existencia de la referida reunión popular reflejó las discrepancias y contradicciones existentes en la UP y en la izquierda con respecto al método político más idóneo para transitar hacia una sociedad socialista. El gobierno de Allende y el PC rechazaron la Asamblea del Pueblo por antirrevolucionaria; y también se opusieron a la formación de instancias de poder paralelo al oficial instigadas por el comicio penquista; persistirían en la tesis de la revolución gradual.

Tras el rechazo gubernamental a la Asamblea del Pueblo, terminó imponiéndose la tesis -al menos en el MAPU- de impulsar las instancias de Poder Popular únicamente surgidas durante el desarrollo del gobierno de Allende y la UP, tales como las Juntas de Abastecimientos y Precios, establecidas en abril de 1972 para colaborar en la función del abasto de alimentos y otros productos a la población.

Falta avanzar en la resolución del porqué surge en Concepción la Asamblea del Pueblo y no en otro lugar. Es posible que los dirigentes de izquierda penquistas fuesen más radicales e impacientes que sus pares de otras partes del país y que -por ello- chocaran con los sectores más apegados a la línea de acción presidencial; pero por de pronto, nos interesó 
especificar mejor las diferencias políticas y las reacciones que implicaron las propuestas alcanzadas por dicha Asamblea, sobretodo porque la radicalización de las izquierdas -y la de las derechas- no se registró de manera uniforme en el país ni en contenido ni en forma. Asimismo, se han interpretado los brotes de Poder Popular como surgidos de la reacción -en base a la experiencia social- por la escasa eficiencia de la vía parlamentaria como medio de desarrollo político social (Salazar 2006); y también dentro de ese marco podría apreciarse el accionar de entidades como las abordadas en esta indagación. Además, falta estudiar la presencia de las organizaciones anti UP Poder Femenino y SOL en Concepción.
Las reacciones de la oposición frente al surgimiento de la Asamblea del Pueblo fueron condenatorias. Así al menos fue la reacción de la Democracia Cristiana local, la cual estimó la convocatoria y a la propia asamblea como una transgresión de la legalidad vigente. Por su parte, el PN consideró a la asamblea una manifestación de las divergencias políticas surgidas al interior de la UP y de la izquierda, en relación con la metodología que debía impulsarse para llevar a cabo la revolución que hiciera transitar a Chile definitivamente hacia el socialismo. Toda esta situación fue considerada por la derecha un elemento más que agitaba la izquierda para avanzar más decididamente hacia un Estado socialista, pero de corte totalitario.

\section{Bibliografía}

\section{Libros, artículos}

Agüero, Javier. 2016. "América Latina durante la Guerra Fría (1947-1989): una introducción”. InterSedes: Revista de las Sedes Regionales, Universidad de Costa Rica, vol. XVII, núm. 35, pp. 4-6; 9 .

Bandeira, Luis Alberto. 2008. Fórmula para el caos: la caída de Salvador Allende (1970 - 1973). Santiago, Debate.

Corvalán, Luis. 1997. De lo vivido y lo peleado. Memorias. Santiago, LOM.

Correa, Sofía; Figueroa, Consuelo; Jocelyn-Holt, Alfredo; Rolle, Claudio; y. Vicuña, Manuel. 2001 Historia del siglo XX chileno. Sudamericana

Díaz Nieva, José. 2014 "En torno a la erosión del Estado de Derecho. Las primeras medidas del gobierno de Salvador Allende: Entre el miedo y la polémica", Derecho Público Iberoamericano - Revista del Centro de Justicia Constitucional, № 5 , octubre de 2014, pp. $173-208$.

Díaz Nieva, José y Valdés Urrutia, Mario. 2015a "Jorge Prat y Acción Nacional (1963 -1966). La antesala del Partido Nacional”, Cuadernos de Historia, № 43, diciembre 2015 pp. 83-108.

Díaz Nieva, José y Valdés Urrutia, Mario, 2015b "Historia electoral de la provincia de Concepción en tiempos de la Unidad Popular", Universidad del Bío - Bío, 35, 2015, pp. 121 - 146.

Díaz Nieva, José. 2015 Patria y Libertad El nacionalismo frente a la Unidad Popular, Santiago, Centro de Estudios Bicentenario.
Encinas Aldapi, Hipólito. 1996. Estado, clase obrera y sociedad civil: la Asamblea Popular de 1971, La Paz. Punto Cero.

Ferreira, Javo, 2005. "Enseñanzas de la Asamblea Popular de 1971", Palabra Obrera, N 9, septiembre de 2005. Sitio web: http://lorci.org/spip.php?article103

Garcés, Mario, 1994. "Izquierda y movimiento popular: Viejas y nuevas tensiones de la política popular chilena", Proposiciones, $\mathrm{N}^{\circ} 24$, Santiago.

Gaudichaud, Franck. 2016. Chile 1970 - 1973. Mil días que estremecieron al mundo. Poder popular, cordones industriales y socialismo durante el gobierno de Salvador Allende. (Traducción de Claudia Marchant), Santiago, LOM.

Goicovic, Igor. 2012. "El Movimiento de Izquierda Revolucionaria (MIR) y la irrupción de la lucha armada en Chile, 1965 - 1990". En: Pablo Pozzi y Claudio Pérez (editores), Historia oral e historia política. Izquierda y lucha armada en América Latina, 1960 - 1990. Santiago, LOM. Pp. 159 - 190.

Goicovic, Igor. 2016. Trabajadores al poder. El Movimiento de Izquierda Revolucionaria (MIR) y el proyecto revolucionario en Chile, Concepción, Escaparate.

Garcés, Joan. 1990. Allende y la experiencia chilena: Las armas de la política. Santiago, BAT.

Jobet, Julio César. 1987. Historia del Partido Socialista, Santiago, Documentas.

Leiva, Sebastián. 2010. Revolución socialista y Poder Popular. Los casos del MIR y PRT-ERP 1970 - 1976, Concepción, 
Escaparate.

Lo Chávez, Damián. 2012. "Comunismo rupturista en Chile (1960 - 1970)", Santiago, Tesis de Licenciatura en Historia, Universidad de Chile.

Lora, Guillermo, 1972. Bolivia: de la Asamblea Popular al golpe fascista, Santiago, Impresora Bío Bío.

Meller, Patricio. 1996. Un siglo de economía política chilena (1890 - 1990), Santiago, Andrés Bello.

Mercado Zavaleta, 1974. René El Poder Dual, México, Siglo $\mathrm{XXI}$.

Monsálvez Araneda, Danny. 2006. "La Asamblea del Pueblo en Concepción. La expresión del Poder Popular". Revista de Historia, Universidad de Concepción, Año 16, volumen 16, Nㅜ 2. Pp. $37-58$.

Monsálvez Araneda, Danny. 2014. Los Bandos militares en Concepción y Talcahuano. Disciplina militar y disciplinamiento social, Concepción, Escaparate.

Pinto Vallejos, Pinto (editor). 2005. Cuando hicimos historia: la experiencia de la Unidad Popular, Santiago, LOM.

Power, Margareth. 2008. La mujer de derecha: el poder femenino y la lucha contra Salvador Allende, 1964 - 1973, Santiago, Centro de Investigaciones Diego Barros Arana.

Salazar, Gabriel. 2006. La violencia política popular en las 'Grandes Alamedas'. La violencia en Chile 1947 - 1987 (Una perspectiva histórico popular), $2^{\mathrm{a}}$ ed., Santiago, LOM.

Salazar, Gabriel, 2011. $2^{\text {a }}$ ed., Conversaciones con Carlos Altamirano. Memorias críticas. Debate.

Strengers, Jeroen. 1991. La Asamblea Popular: Bolivia, 1971, La Paz, Sistema de Documentación e Información Sindical. Valdivia, Verónica; Álvarez, Rolando y Pinto, Julio. 2006. Su revolución contra nuestra revolución Izquierdas y derechas en el Chile de Pinochet (1973 - 1981), Santiago, LOM.
Valdivia, Verónica. 2008. Nacionales y gremialistas. El "parto" de la nueva derecha política chilena, 1964 -1973, Santiago, LOM.

Whelan, James. 1993. Desde las cenizas. Vida, muerte y transfiguración de la democracia en Chile 1833 - 1988, Santiago, Zig - Zag.

Winn, Peter. 2004. Tejedores de la revolución, Santiago, LOM.

\section{Documentos}

Diario de Sesiones del Senado, Legislatura Ordinaria

Farías, Víctor, La Izquierda chilena (1969 - 1973). Documentos para el estudio de su línea estratégica. Berlín, Centro de Estudios Públicos, Tomo I. 2000.

Partido Nacional. Fundamentos doctrinarios y programáticos. Santiago, Impr. El Imparcial, 1967. 1969.

Programa Básico de Gobierno de la Unidad Popular. Santiago,

Programa del Movimiento de Izquierda Revolucionaria, 15 de agosto de 1965

\section{Prensa}

Crónica (C)

El Diario Color (EDC)

El Diario llustrado (EDI)

El Mercurio (EM)

El Sur (ES)

La Discusión (LD)

Patria y Libertad (PyL)

Punto Final (PF)

Qué Pasa (QP)

Tribuna $(T)$ 